Laboratoire de Recherche en Gestion $\&$ Economie

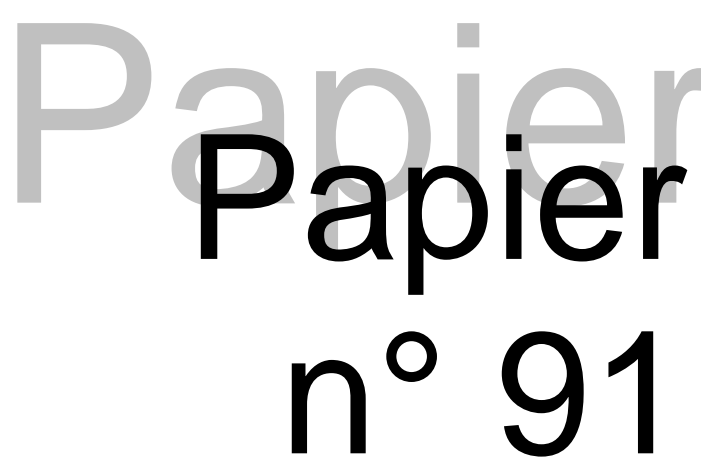

How to solve the St Petersburg Paradox in Rank-Dependent Models ?

\author{
Marie Pfiffelmann
}

Faculté des sciences économiques et de gestion

Octobre 2007

61, avenue de la Forêt Noire 67085 STRASBOURG Cedex

Tél. : (33) 0390242152 Fax : (33) 0390242151 www-ulp.u-strasbg.fr/large 


\title{
How to solve the St Petersburg Paradox in Rank-Dependent Models?
}

\author{
Marie Pfiffelmann*
}

Last version: October 2007

\begin{abstract}
The Cumulative Prospect Theory, as it was specified by Tversky and Kahneman (1992) does not explain the St Petersburg Paradox. This study shows that the solutions proposed in the literature (Blavatskky, 2005; Rieger and Wang, 2006) to guarantee, under rank dependant models, finite subjective utilities for any prospects with finite expected values have to cope with many limitations. In that framework, CPT fails to accommodate both gambling and insurance behavior. We suggested to replace the weighting function generally proposed in the literature with another specification which respects the following properties. 1) In order to guarantee finite subjective values for all prospects with finite expected values, the slope at zero should be finite. 2)To account for the fourfold pattern of risk attitudes, the probability weighting should be strong enough to overcome the concavity of the value function.
\end{abstract}

Keywords : St Petersburg Paradox, Cumulative Prospect Theory, Probability Weighting, Gambling.

JEL Classification : D81, C01.

${ }^{*}$ LaRGE, Faculty of Business and Economics, Louis Pasteur University. Pôle Européen de Gestion et d'Economie, 61 avenue de la Forêt Noire, 67000 Strasbourg, FRANCE. Tel. + 33 (0)3.90.24.21.47 / Fax + 33 (0)3.90.24.20.64. E-mail: pfiffelmann@cournot.u-strasbg.fr. 


\section{Introduction}

The St. Petersburg Paradox posed in 1713 by Nicholas Bernoulli shows that for prospects with infinite expected monetary value decision makers are not willing to pay an infinite sum of money. This observation can be taken as an evidence against expected value theory. In fact, according to this theory introduced by Blaise Pascal, individuals evaluate risky prospects by their expected value. So any decision-maker should accept to pay an infinite amount of money for prospects with infinite expected value. In 1738, Daniel Bernoulli solved the paradox by introducing the idea of diminishing marginal utility. He postulated that individuals valuate prospects not by their expected value but by their expected utility where utility is not linearly related to outcomes but increases at a decreasing rate. So if we consider that individuals preferences are represented by a strictly increasing and concave utility function this paradox can be solved. Since this date, the expected utility (EU) theory was considered (for many years) as a benchmark for describing decision making under risk.

However, the Allais paradox (1953) and many other experimental studies (Slovic et Lichtenstein, 1968; Kahneman and Tversky, 1979) report persistent violations of EU theory. Moreover its predictions of behavior are seriously questioned. On the one hand, individuals preferences for insurance lead to a risk-averse behavior. On the other hand, acceptance of gambling indicates risk-seeking behavior. Two conflicting behavioral choices are therefore observed. The cumulative prospect theory (CPT) developed by Tversky and Kahneman (1992) was then proposed as an alternative model to the well established expected utility model. This theory is based on 4 important features: 1) Utility is defined over gains and losses rather than over final asset position. So risky prospects are evaluated relatively to a reference point. This reference point corresponds to the asset position one expects to reach. 2) The sensitivity relatively to the reference point is decreasing. The value function is then concave for gains and convex for losses. 3) Individuals have asymmetric perception of gains and losses: they are loss-adverse, hence the value function is steeper for losses than for gains. 4) Individuals do not use objective probabilities when evaluating risky prospects. They transform objective probabilities via a weighting function. They overweight the small probabilities of extreme outcomes (events at the upper tail of the distribution). Conversely, they underweight outcomes with average probabilities.

CPT stands for one of the most well-accepted alternatives to expected utility theory because its predictions of behavior are consistent with the recently accumulated empirical evidence on individual preferences. Although this model overwhelmed the EU predictions of behavior, it must cope with other types of difficulties. Blavatskky (2005) emphasized an intrinsic limitation of that model. The overweighting of small probabilities can lead 
to the re-occurrence of the St Petersburg Paradox. He showed that the valuation of a prospect (the subjective utility) by cumulative prospect theory can be infinite. However it is important to notice that this dilemma is not specific to rank dependent models such as CPT. It is now well known that even in expected utility framework the Bernoulli's resolution of the paradox is unsatisfactory. Actually, in EU framework, that is to say when individuals do not transform probabilities, the introduction of a concave utility function can resolve the paradox as it was introduced by N. Bernoulli. But the game can be modified (by making prizes grow sufficiently fast) so that the concavity of the utility function is not sufficient to guarantee a finite expected utility value ${ }^{1}$. Arrow proposed to resolve this problem by only considering distributions with finite expected value. In that case, the concavity of the utility function is sufficient to guarantee, under EU framework, a finite valuation. This assumption is quite realistic because none individuals or organizations can offer a prospect with infinite expected value. However, we cannot implement it under CPT framework. In fact, in cumulative prospect theory, a prospect with finite expected value can have an infinite subjective value (Rieger and Wang, 2006).

The purpose of the present paper is to determine how we can solve this paradox. Blavatskky (2005) and Rieger and Wang (2006) have already proposed some solutions to guarantee finite subjective values for all prospects with finite expected value. In this study, we explore the behavioral implications of these propositions. We establish that if we take them into account, the modified cumulative prospect theory is not anymore consistent with some behavior observed on the market. For example, there are situations where the CPT modified by these propositions cannot anymore accommodate both gambling and insurance behavior.

The paper is structured as follow: Section II reviews the cumulative prospect theory model paying particular attention to the functional form of the value and weighting function. In section III, we present how the paradox occurs under CPT and report the solutions derived by Blavatskyy (2005) and Rieger and Wang (2006) to resolve it. Section IV analyses the behavioral implications of these propositions. In section V, we propose a more appropriate solution to this paradox. Section VI concludes with a summary of our findings.

\section{Cumulative Prospect Theory}

In this section we briefly present the cumulative prospect theory formalized by Tversky and Kahneman in 1992. In a first version (1979) Kahneman and Tversky supposed that decision makers transform individual probabilities directly via a weighting function. This

\footnotetext{
${ }^{1}$ This super paradox was first illustrated by Menger (1934).
} 
assumption leads to preferences that violate the first order stochastic dominance criteria. In the cumulative version, they took into account Quiggin and Yaari's work and applied the probability weighting function to the cumulative probability distribution. Therefore, while attitude towards risk is fully characterized by the value function under expected utility theory, under cumulative prospect theory, attitude towards risk is determined simultaneously by the value function and the cumulative weighing function.

Consider a prospect $X$ defined by:

$$
X=\left(\left(x_{i}, p_{i}\right) i=-m, \ldots n\right)
$$

with $x_{-m}<x_{-m+1}<\ldots .<x_{0}=0<x_{1}<x_{2}<\ldots<x_{n}$.

We have mentioned previously that gains and losses are evaluated differently by individuals. In order to take into account this assumption, the evaluation function $V$ of a prospect $X$ is defined by:

$$
V(X)=V\left(X^{+}\right)+V\left(X^{-}\right)
$$

where $X^{+}=\max (X ; 0)$ et $X^{-}=\min (X ; 0)$.

We set:

$$
\begin{aligned}
V\left(X^{+}\right) & =\sum_{i=0}^{n} \pi_{i}^{+} v\left(x_{i}\right) \\
V\left(X^{-}\right) & =\sum_{i=-m}^{0} \pi_{i}^{-} v\left(x_{i}\right)
\end{aligned}
$$

where $v$ is a strictly increasing value function defined with respect to a reference point satisfying $v\left(x_{0}\right)=v(0)=0$.

$\pi^{+}=\left(\pi_{0}^{+}, \ldots . \pi_{n}^{+}\right)$and $\pi^{-}=\left(\pi_{-m}^{-}, \ldots . \pi_{0}^{-}\right)$are the weighting functions for gains and losses respectively defined by:

$$
\begin{aligned}
& \pi_{n}^{+}=w^{+}\left(p_{n}\right) \\
& \pi_{-m}^{-}=w^{-}\left(p_{-m}\right) \\
& \pi_{i}^{+}=w^{+}\left(p_{i}+\ldots . .+p_{n}\right)-w^{+}\left(p_{i+1}+\ldots .+p_{n}\right) \text { with } 0 \leq \mathrm{i} \leq \mathrm{n}-1 \\
& \pi_{i}^{-}=w^{-}\left(p_{-m}+\ldots .+p_{i}\right)-w^{-}\left(p_{-m}+\ldots .+p_{i-1}\right) \quad \text { with }-m \leq i \leq 0
\end{aligned}
$$


with $w^{+}(0)=0=w^{-}(0)$ and $w^{+}(1)=1=w^{-}(1)$

Consider $F$ the cumulative distribution function of $X$. We notice that $w^{+}\left(p_{i}\right)$ is applied to the decumulative distribution function of $X$ (i.e.))

$$
w^{+}\left(\sum_{j=1}^{n} p_{j}\right)=w^{+}\left(1-F\left(x_{i-1}\right)\right)
$$

whereas $w^{-}\left(p_{i}\right)$ is applied to the cumulative distribution function of $X$

$$
w^{-}\left(\sum_{j=-m}^{i} p_{j}\right)=w^{-}\left(F\left(x_{i}\right)\right)
$$

Tversky and Kahneman (1992) proposed the following functional form for the value function:

$$
v(x)=\left\{\begin{array}{ll}
x^{\alpha} & \text { if } x>0 \\
-\lambda(-x)^{-\beta} & \text { if } x<0
\end{array}\right\}
$$

For $0<\alpha<1$ and $0<\beta<1$ the value function $v$ is concave over gains and convex over losses. It is kinked at the origin and steeper for losses than for gains. The parameter $\lambda$ describes the degree of loss aversion Köbberling and Wakker (2005). Based on experimental evidences, Tversky and Kahneman estimated the values of the parameters $\alpha, \beta$, and $\lambda$ $\alpha=\beta=0.88$ and $\lambda=2.25$.

They proposed the following functional form for the weighting function:

$$
w^{+}(p)=\frac{p^{\gamma+}}{\left[p^{\gamma+}+(1-p)^{\gamma+}\right]^{1 / \gamma+}} \quad w^{-}(p)=\frac{p^{\gamma-}}{\left[p^{\gamma-}+(1-p)^{\gamma-}\right]^{1 / \gamma-}}
$$

For $\gamma<1$, this functional form integrates the overweighting of low probabilities and the greater sensitivity for changes in probabilities for extremely low and extremely high probabilities. The weighting function is concave near 0 and convex near 1 . Tversky and Kahneman estimated the parameters $\gamma^{+}$and $\gamma^{-}$as 0.61 and 0.69. 


\section{The St Petersburg Paradox}

The St Petersburg Paradox is usually explained by the following example: Let's consider a gamble $L$ in which the player gets $2^{n}$ euros when the coins lands heads for the first time at the $n^{\text {th }}$ throw. $L$ has an infinite expected value.

$$
E(L)=\frac{1}{2} \times 2+\left(\frac{1}{2}\right)^{2} \times 2^{2}+\ldots \ldots . .+\left(\frac{1}{2}\right)^{n} \times 2^{n}+\ldots \ldots=\sum_{k=1}^{\infty} 1=+\infty
$$

According to number of experiments, the maximum price an individual is willing to pay for this gamble is around 3 euros. This observation can be taken as an evidence against expected value theory. Daniel Bernoulli (1738) proposed to replace in (1) the monetary value of each outcome with their subjective utility (where the subjective utilities are represented by a strictly concave utility function). In that framework the strictly concave utility function $u(x)=\ln x$ leads to:

$$
U E(L)=\sum_{k=1}^{\infty}\left(\frac{1}{2}\right)^{k} \times \ln \left(2^{k}\right)=2 \ln 2<+\infty
$$

This solution permits to solve this particular paradox. Since this resolution, expected utility theory became, for more than 200 years, the major model of choices under risk. However, empirical evidences have recently showed that EU theory fails to provide a good explanation of individual behavior under risk. These observations have motivated the development of alternative models of choices. One of the most famous is the cumulative prospect theory (presented in the previous section) developed by Tversky and Kahneman (1992).

Even if this model is deemed to be one of the best alternatives to EU theory, it also has to deal with some difficulties. Actually, Blavatskky (2005) established that, under $\mathrm{CPT}$, the overweighting of small probabilities restores the St Petersburg Paradox. Under CPT, the subjective utility $(V)$ of the game described above $(L)$ is given by:

$$
\begin{aligned}
V(L) & =\sum_{n=1}^{+\infty} v\left(2^{n}\right) \times\left[w\left(\sum_{i=n}^{+\infty} 2^{-i}\right)-w\left(\sum_{i=n+1}^{+\infty} 2^{-i}\right)\right] \\
& =\sum_{n=1}^{+\infty} v\left(2^{n}\right) \times\left[w\left(2^{1-n}\right)-w\left(2^{-n}\right)\right]
\end{aligned}
$$

In section 2, we underline that the functional forms proposed for $v$ and $w$ by Tversky and Kahneman are $v(x)=x^{\alpha}$ with $\alpha>0$ and $w(p)=p^{\gamma} /\left(p^{\gamma}+(1-p)^{\gamma}\right)^{1 / \gamma}$ with $0<\gamma<1$. 
As $\lim _{n \longrightarrow+\infty} 2^{1-n}=0$ and $\lim _{n \longrightarrow+\infty} 2^{1-n}=0,\left[p^{\gamma}+(1-p)^{\gamma}\right]^{1 / \gamma}$ converges to unity. In that case, the function $w$, specified by Tversky and Kahneman, can then be approximated by $p^{\gamma}$. According to these elements we can rewrite $V(L)$ as:

$$
\begin{aligned}
V(L) & \approx\left(2^{\gamma}-1\right) \sum_{n=1}^{+\infty} 2^{(\alpha-\gamma) n} \\
& \approx 0,526 \times \sum_{n=1}^{+\infty} 2^{0,27 n} \longrightarrow+\infty
\end{aligned}
$$

One can object that this paradox does not involve a real problem insofar as the expected value of this game is infinite. Actually, it is not realist to assume that an institution can offer a prospect with unlimited expected value (Arrow, 1974). However, Pfiffelmann (2007) and Rieger and Wang (2006) pointed out that, under CPT, a prospect with finite expected value can have infinite subjective utility. Such a result is possible because the weighting function has an infinite slope at zero. Therefore, the more the probability is low, the more the overweighting is important. An extremely small probability can thus be infinitely overweighted. As the value function is unbounded, there are situations for which the subjective value of a consequence weighted by its decision weight can be infinitely high.

Rieger et Wang (2006) characterized situations where this problem can be resolved. They focused on fitting parameterized functional forms to CPT's functions and determined for which parameter combinations the model implies finite subjective value for all lotteries with finite expected value.

Let's consider $V$ the subjective utility under $\mathrm{CPT}^{2}$ :

$$
V(p)=\int_{-\infty}^{0} v(x) \frac{d}{d x}\left(w_{-}(F(x))\right) d x+\int_{0}^{+\infty} v(x) \frac{d}{d x}\left(w_{-}(F(x))\right) d x
$$

where the value function $v$ is continuous, monotone, convex for $x<0$ and concave for $x$ $>0$. Assume that there exists constants $\alpha, \beta>0$ such that:

$$
\begin{aligned}
& \lim _{x \rightarrow+\infty} \frac{v(x)}{x^{\alpha}}=v_{1} \in(0,+\infty) \\
& \lim _{x \longrightarrow-\infty} \frac{|v(x)|}{|x|^{\beta}}=v_{2} \in(0,+\infty)
\end{aligned}
$$

\footnotetext{
${ }^{2}$ For more details on the demonstration see Rieger and Wand (2006).
} 
Assume that the weighting functions $w$ are continuous and strictly increasing from $[0,1]$ to $[0,1]$ such that $w(0)=0$ and $w(1)=1$. Moreover, assume that $w$ is continuously differentiable on $] 0,1\left[\right.$ and that there are constants $\gamma^{+}, \gamma^{-}$such that:

$$
\begin{aligned}
\lim _{y \longrightarrow 0} \frac{w_{-}^{\prime}(y)}{y^{\gamma^{-}-1}} & =w_{1} \quad \in(0,+\infty) \\
\lim _{y \longrightarrow 1} \frac{1-w_{+}^{\prime}(y)}{(1-y)^{\gamma^{+}-1}} & =w_{2} \quad \in(0,+\infty)
\end{aligned}
$$

Consider $p$ a probability distribution for which $E(p)<\infty$. If all the conditions described above are satisfied $V(p)$ is finite if $\alpha<\gamma^{+}$et $\beta<\gamma^{-}$.

Thus if we consider the Tversky and Kahneman's specification for the value and weighting functions, the valuation of any prospect by CPT will be finite only if $\alpha<\gamma^{+}$and $\beta<$ $\gamma^{-}$. The estimates of $\alpha, \beta, \gamma^{+}$and $\gamma^{-}$are usually obtained from parametric fitting to experimental data. The estimated parameters realized by Camerer and Ho (1994) and Wu and Gonzales (1996) are the only one that are consistent with these conditions. In that case, the concavity of the value function is sufficiently strong relative to the probability weighting function to avoid the St Petersburg Paradox.

Rieger and Wang (2006) proposed another solution to avoid the paradox under CPT. They suggested to consider a polynomial of degree three as a weighting function. The specification is given by:

$$
w(p)=\frac{3-3 b}{a^{2}-a+1} \times\left(p^{3}-(a+1) p^{2}+a p\right)+p
$$

with $a \in(0,1)$ et $b \in(0,1)$.

As its slope at zero is finite, this weighting function permits to avoid infinite subjective utilities for all prospects with finite expected value. 


\section{The behavioral implications of the solutions proposed in the literature}

If we take into account the propositions described above, the St Petersburg Paradox will not occur under CPT. But at the same time, this theory will loose a major part of its descriptive power.

\subsection{The Camerer and Ho's (1994) and Wu and Gonzales' (1996) esti- mates}

Rieger and Wang (2006) established that prospects with finite expected value will not have infinite subjective utility if the power coefficient of the value function is lower than the power coefficient of the probability weighting function. Two parameterized versions of CPT are consistent with this condition (Camerer and Ho, 1994; Wu and Gonzales, 1996). Accepting them will solve the paradox. However, they generate other kind of difficulties. Actually, these parameterizations of CPT cannot anymore accommodate the four-fold pattern of risk attitude (risk aversion for most gains and low probability losses, and risk seeking for most losses and low probability gains). For example, these versions of CPT fail to capture the gambling behavior observed on the market and more precisely the tendency of individuals to bet on unlikely gains (Neilson et Stowe, 2002). This pattern is still one of the most fundamental contributions of CPT as it was developed by Tversky and Kahneman. But it can emerge only if the probability weighting over-ride the curvature of the value function (for low probabilities). In fact, in rank dependant models, gambling behavior can be captured only if the overweighting of probabilities is strong enough to compensate the concavity of the value function. When $\alpha$ is lower than $\gamma^{3}$, the convexity of the weighting function cannot overcome the concavity of the value function. In that case, optimism generated by the weighting function does not offset risk aversion resulting from the value function. It is thus impossible to account for gambling behavior ${ }^{4}$. If we consider a value function whose power coefficient is lower than the coefficient of the probability weighting function (as it is suggested by Rieger and Wang), CPT does not restore the St Petersburg Paradox but in return it does not provide a good description of individual behavior under risk.

\footnotetext{
${ }^{3}$ For all usual estimates of $\gamma$.

${ }^{4}$ This fact is illustrated in appendice. We show that with the Camerer and Ho's and Wu and Gonzales' estimates the choice behavior under CPT is not consistent with the very famous lottery games euromillions.
} 


\subsection{The Rieger and Wang's polynomial function}

\subsubsection{Limitations of the specification}

We underline previously that considering a polynomial weighting function instead of the Tversky and Kahneman's specification can solve the paradox. The functional form proposed by Rieger and Wang is given by:

$$
w(p)=\frac{3-3 b}{a^{2}-a+1} \times\left(p^{3}-(a+1) p^{2}+a p\right)+p
$$

with $a \in(0,1)$ et $b \in(0,1)$.

As its slope at zero and unity is finite, the subjective utility of any finite expected value prospects will be finite. However, as the solution proposed above, the behavioral implication of this new specification of CPT does not allow for betting on unlikely gains. The highest slope of this function at zero (when $b=0$ and $a=1$ ) is actually equal to 4 , which is too low. The small probabilities are then not enough overweighted. Therefore the model modified by the Rieger and Wang's weighting function do not imply that individuals insure against unlikely losses or bet on unlikely gains. In order to illustrate this fact, we apply CPT (the version proposed by Tversky and Kahneman and the one modified by Rieger and Wang) to the most popular European lottery: Euromillion. We obtain that with the modification operated by Rieger and Wang, CPT cannot anymore explain the popularity of this very famous game.

\subsubsection{Illustration: the case of Euromillions}

Euromillions is a unique lottery game played every Friday by hundreds of millions of players throughout Europe. One can play by using a playslip that contains six sets of main boards and lucky star boards. Each player selects five numbers on a main board and two numbers on the associated lucky start board to make one entry. A Euromillions lottery ticket costs euro 2. $50 \%$ of the money paid for a ticket goes directly to the operator selling it (in France euro 1 of every euro 2 ticket a player buy will go to the "Francaise des Jeux"). The remaining 50\% of ticket fees goes into the "Common Prize Fund" out of which all prizes are paid. Table 1 represents the percentage share of the fund allocated to each prize with the corresponding probabilities ${ }^{5}$.

We apply the two versions of CPT (the original and the one developed by Rieger and Wang) to this European game. In order to determine the average monetary game

\footnotetext{
${ }^{5}$ We assume that all the booster fund is devoted to the first rank.
} 
Table 1: Euromillions

\begin{tabular}{c|cc}
\hline \hline gains rank & \% Prize Fund & Probability \\
\hline \hline $1^{\text {st }}$ rank & $32 \%+6 \%$ & $\frac{1}{7625560}$ \\
$2^{\text {nd }}$ rank & $7.4 \%$ & $\frac{1}{5448240}$ \\
$3^{\text {th }}$ rank & $2.1 \%$ & $\frac{1}{3632160}$ \\
$4^{\text {th }}$ rank & $1.5 \%$ & $\frac{1}{339002}$ \\
$5^{\text {th }}$ rank & $1 \%$ & $\frac{1}{24214}$ \\
$6^{\text {th }}$ rank & $0.7 \%$ & $\frac{1}{16143}$ \\
$7^{\text {th }}$ rank & $1 \%$ & $\frac{1}{7705}$ \\
$8^{\text {th }}$ rank & $5.1 \%$ & $\frac{1}{550}$ \\
$9^{\text {th }}$ rank & $4.4 \%$ & $\frac{1}{538}$ \\
$10^{\text {th }}$ rank & $4.7 \%$ & $\frac{1}{367}$ \\
$11^{\text {th }}$ rank & $10.1 \%$ & $\frac{1}{102}$ \\
$12^{\text {th }}$ rank & $24 \%$ & $\frac{1}{38}$
\end{tabular}

for each winner at each rank, we assume a number of participants equal to 40 millions (so a prize fund also equal to 40 millions) ${ }^{6}$. The probability to win at the second rank is $\frac{1}{5448240}$, so on average there are 7 winners at this rank. The average gain per winner is then equal to: $\frac{40000000 \times 7.4 \%}{7}=422857.14$. Table 2 displays the results of the game's valuation by $\mathrm{CPT}$ and $\mathrm{CPT}$ modified ${ }^{7}$.

Table 2: Euromillions Valuation

\begin{tabular}{c|c|c|c|c|c}
\hline \hline gains rank & Probabilities & Gains & $v\left(x_{i}\right)$ & $\begin{array}{c}\pi_{i} \\
\text { CPT }\end{array}$ & $\begin{array}{c}\pi_{i} \\
\text { CPT modified }\end{array}$ \\
\hline \hline $1^{\text {st }}$ rank & $1.311 \times 10^{-8}$ & 15200000 & 2089403.44 & $1.55501 \times 10^{-5}$ & $2.34607 \times 10^{-8}$ \\
$2^{\text {nd }}$ rank & $1.835 \times 10^{-7}$ & 422857.14 & 89340.55 & $6.55653 \times 10^{-5}$ & $3.2845 \times 10^{-7}$ \\
$3^{\text {th }}$ rank & $2.753 \times 10^{-7}$ & 76363.63 & 19012.08 & $5.72386 \times 10^{-5}$ & $4.92674 \times 10^{-7}$ \\
$4^{\text {th }}$ rank & $2.949 \times 10^{-6}$ & 5128.2 & 1839.16 & 0.00032463 & $5.27862 \times 10^{-6}$ \\
$5^{\text {th }}$ rank & $4.129 \times 10^{-5}$ & 242.27 & 124.46 & 0.00175136 & $7.38969 \times 10^{-5}$ \\
$6^{\text {th }}$ rank & $6.194 \times 10^{-5}$ & 113.03 & 63.09 & 0.00153935 & 0.000110825 \\
$7^{\text {th }}$ rank & 0.0001297 & 77.05 & 44.7 & 0.00232386 & 0.000232125 \\
$8^{\text {th }}$ rank & 0.0018181 & 28.05 & 17.61 & 0.0160782 & 0.003242095 \\
$9^{\text {th }}$ rank & 0.0018587 & 23.67 & 14.98 & 0.0101514 & 0.003295609 \\
$10^{\text {th }}$ rank & 0.0027247 & 17.25 & 10.99 & 0.0115014 & 0.004796966 \\
$11^{\text {th }}$ rank & 0.0098039 & 10.30 & 6.44 & 0.0290591 & 0.016926816 \\
$12^{\text {th }}$ rank & 0.0263157 & 9.12 & 5.62 & 0.048556 & 0.042932219 \\
No gain & 0.9572 & 0 & -4.14 & 0.86336 & 0.912226886 \\
V $(\mathbf{X})$ & & & & $\mathbf{3 7 . 9 4}$ & $\mathbf{3 . 1 4}$
\end{tabular}

The valuation of the game with cumulative prospect theory, as it was developed by Tversky and Kahneman, is positive. But if we substitute the inverse S- shape probability

\footnotetext{
${ }^{6}$ The prize fund reached euro 38734739 the 12 October 2007, and euro 50916665 the 20 September.

${ }^{7}$ We consider a reference point of euro 2 .
} 
weighting function specified by Tversky and Kahneman with the one proposed by Rieger and Wang ${ }^{8}$ the subjective utility becomes negative. Decision makers who transform probabilities via the polynomial weighting function would prefer keeping the price of the lottery ticket rather than participate in the lottery. This new version of CPT is therefore not able to explain the popularity of public lotteries. This limitation is quite severe, since betting on unlikely gains is one of the most important stylized facts that cumulative prospect theory aims to predict.

\section{An alternative weighting function}

Section III underlines that CPT should be remodeled if we want to apply it to problems of choices. The occurrence of the paradoxe under CPT comes from the overweighting of small probabilities. As the slope of the weighting function at zero is infinity, an extremely small probability can be infinitely overweighted. And as the slope of the value function do not decrease for the high values of outcomes, the subjective value of a consequence weighted by its decision weight can be infinitely high. In order to overcome this difficulty, we propose an alternative weighting function that avoids infinite values for subjective utility. This function should respect the following properties:

1. $w(0)=0$ and $w(1)=1$

2. $w$ strictly increasing on $[0,1]$.

3. $w$ continuously differentiable on $[0,1]$, with $w^{\prime}(0)$ et $w^{\prime}(1) \neq \infty$. We underlined previously that if the slope at zero is too low, CPT cannot accommodate the gambling and insurance behavior observed on the market. Therefore $w^{\prime}(0)$ should be sufficiently strong.

\subsection{A polynomial specification}

Before attempting to build a new weighting function, it is important to clarify a point. The evidences presented previously criticize the way probabilities are transformed near 0 and 1 with the weighting function proposed by Tversky and Kahneman. These evidences challenge the specification of the function but not the experimental data Tversky and Kahneman have obtained. In fact, the problem does not concern the individual preferences they have elicited but the functional form of the function. We agree (and there is no doubt about that) that an inverse $\mathrm{S}$ shape weighting function, first concave then convex really

\footnotetext{
${ }^{8}$ In table 2, we took for the computation of $\pi: a=0.4$ and $b=0.5$. Nevertheless, the same result (a negative valuation) is obtained with any other combinations of $a$ and $b$.
} 
represents the way individuals transform probabilities. The difficulties related to the use of the Tversky and Kahneman's weighting function only concerns its slope at 0 and 1 . To overcome them, we consider a polynomial weighting function because the slope of this kind of specifications is always finite within the interval considered. As we do not challenge the experimental results Tversky and Kahneman have obtained, we estimate the coefficients of the polynomial from the points of the functional they have proposed. We remind that the slope at zero must be sufficiently strong to overcome the slope of the value function. Other than CPT won't be able to explain preferences for gambling and insurance. Therefore we cannot consider a simple functional as the polynomial of degree three proposed by Rieger and Wang. Actually if we process to a polynomial approximation at the order three, the slope at zero won't be strong enough to accommodate gambling and insurance behavior. A solution would consist in considering a polynomial characterized partly by small exponents because it permits to well captured the overweighting of small probabilities. In this work, we set the values of the exponents so that the curve is as close as possible to the original curve. Let the weighting function given by:

$$
w(p)=a p+b p^{1.1}+c p^{1.15}+d p^{1.2}+e p^{2}+f p^{2.5}+g p^{6}
$$

with $a+b+c+d+e+f+g=1$ such as $w(1)=1$.

According to these elements we can rewrite $w$ as :

$$
\begin{aligned}
w(p) & =a p+b p^{1.1}+c p^{1.15}+d p^{1.2}+e p^{2}+f p^{2.5}+(1-a-b-c-d-e-f) p^{6} \\
w(p)-p^{6} & =a\left(p-p^{6}\right)+b\left(p^{1.1}-p^{6}\right)+c\left(p^{1.15}-p^{6}\right)+d\left(p^{1.2}-p^{6}\right)+e\left(p^{2}-p^{6}\right)+j\left(p^{2.5}-p^{6}\right) \\
y & =a x_{1}+b x_{2}+c x_{3}+d x_{4}+e x_{5}+f x_{6}
\end{aligned}
$$

with $y=w(p)-p^{6}, x_{1}=\left(p-p^{6}\right), \ldots . . x_{6}=\left(p^{2.5}-p^{6}\right)$

In order to estimate the coefficients $a, \ldots, f$, we built 1027 observations from the Tversky and Kahneman's weighting function ${ }^{9}$. Table 3 (respectively 4 ) displays the results of the estimates for gains (respectively losses) ${ }^{10}$.

\footnotetext{
${ }^{9}$ We assume that $\gamma^{+}=0,61$ et $\gamma^{-}=0,69$.

${ }^{10}$ To test the stability of the coefficients, we realized 14 regressions by removing randomly $5 \%$ of the observations. We mainly focused on $a$ which represents the slope of the function at zero. For gains, its average estimate is 2215.45 and the standard error equals to $1.70 \%$.

In this study, we kept the estimate the closest to the mean.
} 
Table 3: Results of the estimates for gains

\begin{tabular}{c|rrr}
\hline \hline Variable & Coefficient & T-Stat & Prob \\
\hline \hline$x_{1}$ & 2215.004 & 14.98 & 0.000 \\
$x_{2}$ & -19080.29 & -15.23 & 0.000 \\
$x_{3}$ & 30702.47 & 15.39 & 0.000 \\
$x_{4}$ & -13963.80 & -15.55 & 0.000 \\
$x_{5}$ & 202.1941 & 18.84 & 0.000 \\
$x_{6}$ & -76.95053 & -20.95 & 0.000
\end{tabular}

Table 4: Results of the estimates for losses

\begin{tabular}{c|rrr}
\hline \hline Variable & Coefficient & T-Stat & Prob \\
\hline \hline$x_{1}$ & 1295.432 & 15.57 & 0.000 \\
$x_{2}$ & -11162.53 & -15.73 & 0.000 \\
$x_{3}$ & 17972.97 & 15.91 & 0.000 \\
$x_{4}$ & -8180.233 & -16.09 & 0.000 \\
$x_{5}$ & 119.3246 & 19.67 & 0.000 \\
$x_{6}$ & -45.40450 & -21.9 & 0.000
\end{tabular}

The weighting function is thus given by:

$$
\begin{aligned}
w(p)= & 2215,003 p-19080,29 p^{1,1}+30702,47 p^{1,15}-13963,8 p^{1,2} \\
& +202,1941 p^{2}-76,95053 p^{2,5}+2,37243 p^{6}
\end{aligned}
$$

This functional form has a finite slope at zero and one. It is strictely increasing on $[0,1]$ and satisfies the overweighting of small probabilities and underweighting of moderate and high probabilities.

\subsection{A non-polynomial form}

We underline previously that the limitations of the weighting function proposed by Tversky and Kahneman only concerns its slope at 0 and 1 . Concerning the remainder of the interval, this specification perfectly characterizes attitudes towards probabilities. We can thus keep the global framework of these functional form and modify it lightly in a such way that the slopes at the extremities of the interval are not anymore infinite.

Let this functional form be given by:

$$
w_{1}(p)=\frac{(p+a)^{\gamma_{1}}}{\left[(p+a)^{\gamma_{1}}+(1-(p+a))^{\gamma_{1}}\right]^{\frac{1}{\gamma_{1}}}}-b
$$


with $a=0+\varepsilon, w^{T+K}(a)=b$ and $0,3<\gamma_{1}<1$.

This specification is stepest near zero and shallower in the middle. It satisfies the properties of subadditivity and is first concave then convex. The condition $w_{1}(0)=0$ is satisfied. At last, its slope is finite at zero. That one can be written as:

$$
a^{\gamma_{1}}\left((1-a)^{\gamma_{1}}\right)^{\frac{-1}{\gamma_{1}}} \times \gamma_{1}\left(\frac{1}{a}+\frac{(1-a)^{-1+\gamma_{1}}-a^{-1+\gamma_{1}}}{\left.\left((1-a)^{\gamma_{1}}+a^{+\gamma_{1}}\right) \gamma_{1}\right)}\right)
$$

Note that on $[1-a, 1], w_{1}(p)$ is not defined. We have to modifiy the specification for high values of $p$. Let's consider this functional form:

$$
w_{2}(p)=\frac{(p-c)^{\gamma_{2}}}{\left[(p-c)^{\gamma_{2}}+(1-(p-c))^{\gamma_{2}}\right]^{\frac{1}{\gamma^{2}}}}+d
$$

with $c=0+\varepsilon, d$ such as $w_{2}(1)=1$ and $w_{2}$ strictly increasing and convex.

The weighting function can thus be given by:

$$
\begin{aligned}
w(p) & =\frac{(p+a)^{\gamma_{1}}}{\left[(p+a)^{\gamma_{1}}+(1-(p+a))^{\gamma_{1}}\right]^{\frac{1}{\gamma_{1}}}}-b \text { pour } p \in[0, h] \\
& \left.\left.=\frac{(p-c)^{\gamma_{2}}}{\left[(p-c)^{\gamma_{2}}+(1-(p-c))^{\gamma_{2}}\right]^{\frac{1}{\gamma^{2}}}}+d \text { pour } p \in\right] h, 1\right]
\end{aligned}
$$

The value of $h$ is chosen in such a way that $w$ is strictly increasing on $[0,1] . h$ is thus the solution of: $w_{1}(p)=w_{2}(p)$. $w$ is first strictly concave and then strictly convex only if $\gamma_{1}>\gamma_{2}{ }^{11}$. At last, as the slope at 1 and 0 is identical in the specification proposed by Tversky and Kahneman, we assume that $w_{1}^{\prime}(0)=w_{2}^{\prime}(1)$.

In this study we set the values of $a$ and $c$ in such a way that the slope at 0 and 1 equals to 2200 for gains and 1300 for losses. These values are not arbitrarily chosen but correspond to the slopes we have obtained in the previous section. Thus for gains, we determine $a$ and $c$ by resolving the following system:

\footnotetext{
${ }^{11}$ If $\gamma_{1}=\gamma_{2}, w$ re-becomes concave when $w_{2}$ replace $w_{1}$, whatever the value of $h$.
} 


$$
\begin{aligned}
& a^{\gamma_{1}}\left((1-a)^{\gamma_{1}}\right)^{\frac{-1}{\gamma_{1}}} \times \gamma_{1}\left(\frac{1}{a}+\frac{(1-a)^{-1+\gamma_{1}}-a^{-1+\gamma_{1}}}{\left.\left((1-a)^{\gamma_{1}}+a^{+\gamma_{1}}\right) \gamma_{1}\right)}\right)=2200 \\
& \frac{\left((1-c)^{\gamma_{2}}+c^{\gamma_{2}}\right)^{-\frac{1+\gamma_{2}}{\gamma_{2}}} \times\left((1-c)^{\gamma_{2}} \times c-c^{\gamma_{2}}+c^{1+\gamma_{2}}\right)}{(c-1) \times c}=2200
\end{aligned}
$$

Applying the same method for losses, we obtain the following weighting function:

$$
\begin{aligned}
w_{1}^{+}(p)= & \frac{\left(p+7.57 \times 10^{-10}\right)^{0.61}}{\left[\left(p+7.57 \times 10^{-10}\right)^{0.61}+\left(1-\left(p+7.57 \times 10^{-10}\right)\right)^{0.61}\right]^{\frac{1}{0.61}}}-2.7307 \times 10^{-6} \\
& \text { for } p \in[0 ; 0.9999999] \\
w_{2}^{+}(p)= & \frac{\left(p-5.585 \times 10^{-9}\right)^{0.6}}{\left[\left(p-5.585 \times 10^{-9}\right)^{0.6}+\left(1-\left(p-5.585 \times 10^{-9}\right)\right)^{0.6}\right]^{\frac{1}{0.6}}}+1.8621 \times 10^{-5} \\
& \text { for } p \in] 0.9999999 ; 1] \\
w_{1}^{-}(p)= & \frac{\left(p+2.721 \times 10^{-11}\right)^{0.69}}{\left[\left(p+2.721 \times 10^{-11}\right)^{0.69}+\left(1-\left(p+2.721 \times 10^{-11}\right)\right)^{0.69}\right]^{\frac{1}{0.69}}}-5.1281 \times 10^{-8} \\
& \text { for } p \in[0 ; 0.9999999987] \\
w_{2}^{-}(p)= & \frac{\left(p-1.8549 \times 10^{-10}\right)^{0.68}}{\left[\left(p-1.8549 \times 10^{-10}\right)^{0.68}+\left(1-\left(p-1.8549 \times 10^{-10}\right)\right)^{0.68}\right]^{\frac{1}{0.68}}}+3.547 \times 10^{-7} \\
& \text { pour } p \in] 0.9999999987 ; 1]
\end{aligned}
$$

The specification of these two weighting functions has a finite slope at zero. It permits to avoid infinite subjective utility and thus overcomes the difficulties linked to the use of rank dependant models. These functional forms do not imply, as the one proposed 
by Rieger and Wang, no risk seeking behavior over unlikely gains and no risk aversion over unlikely losses. The slope at zero is sufficiently strong: the probability weighting can then over ride the curvature of the value function. CPT does not fail to explain gambling behavior $^{12}$.

\section{Conclusion}

The aim of this study was to determine how we can solve the St Petersburg Paradox in rank dependant models. First, we established that the solutions proposed in the literature lead to other kind of difficulties. We underlined that if we take them into account, the probability weighting won't be strong enough to compensate the concavity of the value function. In that case, CPT cannot accomodate both gambling and insurance behavior. This theory will then loose a major part of its descriptive power. In a second part, we proposed an alternative way to fix the infinite subjective utility's problem. As Rieger and Wang (2006), we suggested to consider an alternative weighting function whose slope at zero is not infinite. In that case, the subjective value of any prospects won't be infinitely high. Nevertheless, in order to preserve the fourforld pattern of risk attitudes, we set a specification whose shape dominates (for low probabilities) the value function. Thanks to this requirement, the overweighting of small probabilities reverses risk averse (respectively risk seeking) behavior for gains (respectively losses) generated by the value function. CPT won't fail to to provide a good description of individual behavior under risk.

\section{References}

Arrow, K. J. (1974): "The Use of Unbounded Functions in Expected-Utility Maximization: Response," The Quaterly Journal of Economics, 88, 136-138.

Bernoulli, D. (1738): "Specimen Theoriae Novae de Mensura Sortis," Commentarii Academiae Scientiarum Imperialis Petropolitanae, 5, 175-192.

(1954, Edition originale, 1738): "Exposition of a new Theory of the Measurement of Risk," Econometrica, 22, 123-136.

Blavatskyy, P. (2005): "Back to the St Petersburg Paradox?," Management Science, $51,677-678$.

\footnotetext{
${ }^{12}$ In appendice, we show that the subjective utility of the euromillions lottery is positive for individuals whose preferences are represented by the weighting functions.
} 
Camerer, C. F., And T. Ho (1994): "Violations of the Betweenness Axiom and Nonlinearity in Probability," Journal of Risk and Uncertainty, 8, 167-196.

Kahneman, D., And A. Tversky (1979): "Prospect Theory : An Analysis of Decision under Risk," Econometrica, 47, 263-291.

Köbberling, V., And P. Wakker (2005): "An Index of Loss Aversion," Journal of Economic Theory, 122, 119-131.

Menger, K. (1934): "Das Unsicherheitsmoment in der Wertlehre," Zeitschrift Nationalökonomie, 51, 459-485.

NeILson, W., And J. Stowe (2002): "A further Examination of Cumulative Prospect Theory Parameterizations," Journal of Risk and Uncertainty, 24, 31-46.

Pfiffelmann, M. (2007): "Which Optimal Design for LLDA?," Working paper, LARGE and DULBEA.

Quiggin, J. (1982): "A Theory of Anticipated Utility," Journal of Economic Behavior and Organization, 3, 323-343.

Rieger, M., And M. Wang (2006): "Cumulative Prospect Theory and the St Petersburg Paradox," Economic Theory, 28, 665-679.

Slovic, P., And S. Lichtenstein (1968): "The Relative Importance of Probabilities and Payoffs in Risk Taking," Journal of Experimental Psychology, 78, 1-18.

Tversky, A., And D. Kahneman (1992): "Advances in Prospect Theory : Cumulative Representation of Uncertainty," Journal of Risk and Uncertainty, 5, 297-323.

Wu, G., and R. Gonzalez (1996): "Curvature of the Probability Weighting Function," Management Science, 42, 1676-1690.

YAARI, M. (1987): "The Dual Theory of Choice under Risk," Econometrica, 55, 95-115.

\section{Appendice}

Table 5 displays the results of euromillions' valuation by CPT with Camerer and Ho (1994) and Wu and Gonzales (1996) estimates ${ }^{13}$.

\footnotetext{
${ }^{13}$ We consider a reference point of euro 2 .
} 
Table 5: Euromillions Valuation

\begin{tabular}{c|c||c|c||c|c}
\hline \hline Probabilities & Gains & $\begin{array}{c}v\left(x_{i}\right) \\
\text { Camerer Ho }\end{array}$ & $\begin{array}{c}\pi_{i} \\
\text { Camerer Ho }\end{array}$ & $\begin{array}{c}v\left(x_{i}\right) \\
\text { Wu Gonzales }\end{array}$ & $\begin{array}{c}\pi_{i} \\
\text { Wu Gonzales }\end{array}$ \\
\hline \hline $1.311 \times 10^{-8}$ & 15200000 & 454.236 & $3.85332 \times 10^{-5}$ & 5426.9851 & $2.5322 \times 10^{-6}$ \\
$1.835 \times 10^{-7}$ & 422857.14 & 120.695 & 0.000136992 & 842.59648 & $1.478610^{-5}$ \\
$2.753 \times 10^{-7}$ & 76363.63 & 64.07134 & 0.000111006 & 346.01515 & $1.4926 \times 10^{-5}$ \\
$2.949 \times 10^{-6}$ & 5128.2 & 23.58438 & 0.000581451 & 84.936411 & $9.935 \times 10^{-5}$ \\
$4.129 \times 10^{-5}$ & 242.27 & 7.60087 & 0.002775051 & 17.296997 & 0.0006838 \\
$6.194 \times 10^{-5}$ & 113.03 & 5.7125 & 0.002260728 & 11.578418 & 0.0006947 \\
0.0001297 & 77.05 & 4.94189 & 0.003262787 & 9.4449954 & 0.0011434 \\
0.0018181 & 28.05 & 3.340792 & 0.020489824 & 5.4477971 & 0.0095197 \\
0.0018587 & 23.67 & 3.120927 & 0.01197572 & 4.9507266 & 0.0069054 \\
0.0027247 & 17.25 & 2.740316 & 0.01302709 & 4.1237036 & 0.0084206 \\
0.0098039 & 10.30 & 2.188255 & 0.0311254 & 3.0059076 & 0.0235416 \\
0.0263157 & 9.12 & 2.067367 & 0.04819050 & 2.7751710 & 0.0451533 \\
0.9572 & 0 & -2.90779 & 0.7638842 & -3.226399 & 0.8742871 \\
$\mathbf{V}(\mathbf{X})$ & & & $\mathbf{- 1 . 8 0}$ & & $\mathbf{- 2 . 4 3}$
\end{tabular}

In both case the subjective utility of one Euromillions ticket is negative. We can generalize this result and show (for any value of $\gamma$ greater than 0.4 ) that if we consider a power coefficient for the value function greater than the power coefficient of the weighting function, the subjective utility of this game is always negative.

Table 6 displays the results of euromillions' valuation by considering the weighting functions defined in section $5^{14}$.

Table 6: Euromillions Valuation

\begin{tabular}{|c|c|c|c|c|}
\hline Probabilities & Gains & $v\left(x_{i}\right)$ & $\pi_{i}^{1}$ & $\pi_{i}^{2}$ \\
\hline $1.311 \times 10^{-8}$ & 15200000 & 20089403.44 & $9.9 .90096 \times 10^{-6}$ & $1.3371 \times 10^{-6}$ \\
\hline $1.835 \times 10^{-7}$ & 422857.14 & 89340.55 & $9.50558 \times 10^{-5}$ & $6.5217 \times 10^{-5}$ \\
\hline $2.753 \times 10^{-7}$ & 76363.63 & 19012.08 & 0.00011415 & $5.7184 \times 10^{-5}$ \\
\hline $2.949 \times 10^{-6}$ & 5128.2 & 1839.16 & 0.000864002 & 0.0003245 \\
\hline $4.129 \times 10^{-5}$ & 242.27 & 124.46 & 0.005956235 & 0.0017513 \\
\hline $6.194 \times 10^{-5}$ & 113.03 & 63.09 & 0.005239292 & 0.0015393 \\
\hline 0.0001297 & 77.05 & 44.7 & 0.007202387 & 0.0023238 \\
\hline 0.0018181 & 28.05 & 17.61 & 0.029688009 & 0.0160782 \\
\hline 0.0018587 & 23.67 & 14.98 & 0.00833742 & 0.0101514 \\
\hline 0.0027247 & 17.25 & 10.99 & 0.00547187 & 0.0115014 \\
\hline 0.0098039 & 10.30 & 6.44 & 0.01083462 & 0.0290591 \\
\hline 0.0263157 & 9.12 & 5.62 & 0.0373534 & 0.0485568 \\
\hline 0.9572 & 0 & -4.14 & 0.8862328 & 0.8633637 \\
\hline $\mathbf{V}(\mathbf{X})$ & & & 31.74 & 33.36 \\
\hline
\end{tabular}

${ }^{14}$ We consider a reference point of euro 2 . 


\section{PAPIERS}

\section{Laboratoire de Recherche en Gestion \& Economie (LARGE)}

D.R. $n^{\circ} 1$ "Bertrand Oligopoly with decreasing returns to scale", J. Thépot, décembre 1993

D.R. $\mathrm{n}^{\circ} 2$ "Sur quelques méthodes d'estimation directe de la structure par terme des taux d'intérêt", P. Roger - N. Rossiensky, janvier 1994

D.R. $n^{\circ} 3$ "Towards a Monopoly Theory in a Managerial Perspective", J. Thépot, mai 1993

D.R. n 4 "Bounded Rationality in Microeconomics", J. Thépot, mai 1993

D.R. n 5 "Apprentissage Théorique et Expérience Professionnelle", J. Thépot, décembre 1993

D.R. $n^{\circ} 6 \quad$ "Stratégic Consumers in a Duable-Goods Monopoly", J. Thépot, avril 1994

D.R. n 7 "Vendre ou louer ; un apport de la théorie des jeux", J. Thépot, avril 1994

D.R. $n^{\circ} 8$ "Default Risk Insurance and Incomplete Markets", Ph. Artzner - FF. Delbaen, juin 1994

D.R. n 9 "Les actions à réinvestissement optionnel du dividende", C. Marie-Jeanne - P. Roger, janvier 1995

D.R. $\mathrm{n}^{\circ} 10 \quad$ "Forme optimale des contrats d'assurance en présence de coûts administratifs pour l'assureur", S. Spaeter, février 1995

D.R. n 11 "Une procédure de codage numérique des articles", J. Jeunet, février 1995

D.R. $n^{\circ} 12$ Stabilité d'un diagnostic concurrentiel fondé sur une approche markovienne du comportement de rachat du consommateur", N. Schall, octobre 1995

D.R. $n^{\circ} 13$ "A direct proof of the coase conjecture", J. Thépot, octobre 1995

D.R. nº 14 "Invitation à la stratégie", J. Thépot, décembre 1995

D.R. n 15 "Charity and economic efficiency", J. Thépot, mai 1996 
D.R. $n^{\circ} 16$ "Princing anomalies in financial markets and non linear pricing rules", P. Roger, mars 1996

D.R. n 17 "Non linéarité des coûts de l'assureur, comportement de prudence de l'assuré et contrats optimaux", S. Spaeter, avril 1996

D.R. $n^{\circ} 18$ "La valeur ajoutée d'un partage de risque et l'optimum de Pareto : une note", L. Eeckhoudt - P. Roger, juin 1996

D.R. $\mathrm{n}^{\circ} 19$ "Evaluation of Lot-Sizing Techniques : A robustess and Cost Effectiveness Analysis", J. Jeunet, mars 1996

D.R. n 20 "Entry accommodation with idle capacity", J. Thépot, septembre 1996

D.R. n 21 "Différences culturelles et satisfaction des vendeurs : Une comparaison internationale", E. Vauquois-Mathevet - J.Cl. Usunier, novembre 1996

D.R. $\mathrm{n}^{\circ} 22$ "Evaluation des obligations convertibles et options d'échange", A. Schmitt - F. Home, décembre 1996

D.R n 23 "Réduction d'un programme d'optimisation globale des coûts et diminution du temps de calcul, J. Jeunet, décembre 1996

D.R. $n^{\circ} 24$ "Incertitude, vérifiabilité et observabilité : Une relecture de la théorie de l'agence", J. Thépot, janvier 1997

D.R. $\mathrm{n}^{\circ} 25$ "Financement par augmentation de capital avec asymétrie d'information : l'apport du paiement du dividende en actions", C. Marie-Jeanne, février 1997

D.R. $\mathrm{n}^{\circ} 26$ "Paiement du dividende en actions et théorie du signal", C. Marie-Jeanne, février 1997

D.R. n 27 "Risk aversion and the bid-ask spread", L. Eeckhoudt - P. Roger, avril 1997

D.R. $n^{\circ} 28$ "De l'utilité de la contrainte d'assurance dans les modèles à un risque et à deux risques", S. Spaeter, septembre 1997

D.R. $n^{\circ} 29$ "Robustness and cost-effectiveness of lot-sizing techniques under revised demand forecasts", J. Jeunet, juillet 1997

D.R. $n^{\circ} 30$ "Efficience du marché et comparaison de produits à l'aide des méthodes d'enveloppe (Data envelopment analysis)", S. Chabi, septembre 1997

D.R. n 31 "Qualités de la main-d'œuvre et subventions à l'emploi : Approche microéconomique", J. Calaza - P. Roger, février 1998

D.R n 32 "Probabilité de défaut et spread de taux : Etude empirique du marché français", M. Merli - P. Roger, février 1998

D.R. n 33 "Confiance et Performance : La thèse de Fukuyama", 


\section{J.Cl. Usunier - P. Roger, avril 1998}

D.R. $n^{\circ} 34$ "Measuring the performance of lot-sizing techniques in uncertain environments", J. Jeunet - N. Jonard, janvier 1998

D.R. n 35 "Mobilité et décison de consommation : premiers résultas dans un cadre monopolistique", Ph. Lapp, octobre 1998

D.R. $\mathrm{n}^{\circ} 36$ "Impact du paiement du dividende en actions sur le transfert de richesse et la dilution du bénéfice par action", C. Marie-Jeanne, octobre 1998

D.R. n ${ }^{\circ} 37$ "Maximum resale-price-maintenance as Nash condition", J. Thépot, novembre 1998

D.R. $\mathrm{n}^{\circ} 38$ "Properties of bid and ask prices in the rank dependent expected utility model", P. Roger, décembre 1998

D.R. n 39 "Sur la structure par termes des spreads de défaut des obligations », Maxime Merli / Patrick Roger, septembre 1998

D.R. $n^{\circ} 40 \quad$ "Le risque de défaut des obligations : un modèle de défaut temporaire de l'émetteur", Maxime Merli, octobre 1998

D.R. n ${ }^{\circ} 41$ "The Economics of Doping in Sports", Nicolas Eber / Jacques Thépot, février 1999

D.R. $\mathrm{n}^{\circ} 42$ "Solving large unconstrained multilevel lot-sizing problems using a hybrid genetic algorithm", Jully Jeunet, mars 1999

D.R n 43 "Niveau général des taux et spreads de rendement", Maxime Merli, mars 1999

D.R. $\mathrm{n}^{\circ} 44$ "Doping in Sport and Competition Design", Nicolas Eber / Jacques Thépot, septembre 1999

D.R. n 45 "Interactions dans les canaux de distribution", Jacques Thépot, novembre 1999

D.R. n 46 "What sort of balanced scorecard for hospital", Thierry Nobre, novembre 1999

D.R. n 47 "Le contrôle de gestion dans les PME", Thierry Nobre, mars 2000

D.R. n ${ }^{\circ} 48$ "Stock timing using genetic algorithms", Jerzy Korczak - Patrick Roger, avril 2000

D.R. n 49 "On the long run risk in stocks : A west-side story", Patrick Roger, mai 2000

D.R. $\mathrm{n}^{\circ} 50$ "Estimation des coûts de transaction sur un marché gouverné par les ordres : Le cas des composantes du CAC40", Laurent Deville, avril 2001

D.R. $n^{\circ} 51$ "Sur une mesure d'efficience relative dans la théorie du portefeuille de Markowitz", Patrick Roger / Maxime Merli, septembre 2001 
D.R. $n^{\circ} 52$ "Impact de l'introduction du tracker Master Share CAC 40 sur la relation de parité callput", Laurent Deville, mars 2002

D.R. n 53 "Market-making, inventories and martingale pricing", Patrick Roger / Christian At / Laurent Flochel, mai 2002

D.R. $n^{\circ} 54$ "Tarification au coût complet en concurrence imparfaite", Jean-Luc Netzer / Jacques Thépot, juillet 2002

D.R. $n^{\circ} 55$ "Is time-diversification efficient for a loss averse investor ?", Patrick Roger, janvier 2003

D.R. $\mathrm{n}^{\circ} 56$ “Dégradations de notations du leader et effets de contagion”, Maxime Merli / Alain Schatt, avril 2003

D.R. n 57 “Subjective evaluation, ambiguity and relational contracts”, Brigitte Godbillon, juillet 2003

D.R. $n^{\circ} 58$ "A View of the European Union as an Evolving Country Portfolio", Pierre-Guillaume Méon / Laurent Weill, juillet 2003

D.R. n 59 “Can Mergers in Europe Help Banks Hedge Against Macroeconomic Risk ?”, Pierre-Guillaume Méon / Laurent Weill, septembre 2003

D.R. $n^{\circ} 60$ "Monetary policy in the presence of asymmetric wage indexation", Giuseppe Diana / Pierre-Guillaume Méon, juillet 2003

D.R. $n^{\circ} 61$ “Concurrence bancaire et taille des conventions de services”, Corentine Le Roy, novembre 2003

D.R. n 62 “Le petit monde du CAC 40”, Sylvie Chabi / Jérôme Maati

D.R. $n^{\circ} 63$ "Are Athletes Different? An Experimental Study Based on the Ultimatum Game”, Nicolas Eber / Marc Willinger

D.R. n 64 "Le rôle de l'environnement réglementaire, légal et institutionnel dans la défaillance des banques : Le cas des pays émergents”, Christophe Godlewski, janvier 2004

D.R. $n^{\circ} 65$ "Etude de la cohérence des ratings de banques avec la probabilité de défaillance bancaire dans les pays émergents”, Christophe Godlewski, Mars 2004

D.R. n 66 "Le comportement des étudiants sur le marché du téléphone mobile : Inertie, captivité ou fidélité ?”, Corentine Le Roy, Mai 2004

D.R. $n^{\circ} 67$ "Insurance and Financial Hedging of Oil Pollution Risks”, André Schmitt / Sandrine Spaeter, September, 2004

D.R. $\mathrm{n}^{\circ} 68$ "On the Backwardness in Macroeconomic Performance of European Socialist Economies”, Laurent Weill, September, 2004

D.R. $n^{\circ} 69$ "Majority voting with stochastic preferences: The whims of a committee are smaller than the whims of its members”, Pierre-Guillaume Méon, September, 2004 
D.R. $\mathrm{n}^{\circ} 70$ "Modélisation de la prévision de défaillance de la banque : Une application aux banques des pays émergents”, Christophe J. Godlewski, octobre 2004

D.R. $\mathrm{n}^{\circ} 71$ "Can bankruptcy law discriminate between heterogeneous firms when information is incomplete ? The case of legal sanctions", Régis Blazy, october 2004

D.R. n 72 “La performance économique et financière des jeunes entreprises”, Régis Blazy/Bertrand Chopard, octobre 2004

D.R. $\mathrm{n}^{\circ} 73$ "Ex Post Efficiency of bankruptcy procedures : A general normative framework”, Régis Blazy / Bertrand Chopard, novembre 2004

D.R. n 74 “Full cost pricing and organizational structure”, Jacques Thépot, décembre 2004

D.R. $\mathrm{n}^{\circ} 75$ "Prices as strategic substitutes in the Hotelling duopoly”, Jacques Thépot, décembre 2004

D.R. n 76 "Réflexions sur l'extension récente de la statistique de prix et de production à la santé et à l'enseignement”, Damien Broussolle, mars 2005

D. R. n 77 "Gestion du risque de crédit dans la banque : Information hard, information soft et manipulation ”, Brigitte Godbillon-Camus / Christophe J. Godlewski

D.R. n 78 "Which Optimal Design For LLDAs”, Marie Pfiffelmann

D.R. $\mathrm{n}^{\circ} 79$ “Jensen and Meckling 30 years after : A game theoretic view”, Jacques Thépot

D.R. n 80 “Organisation artistique et dépendance à l'égard des ressources”, Odile Paulus, novembre 2006

D.R. $n^{\circ} 81$ "Does collateral help mitigate adverse selection? A cross-country analysis”, Laurent Weill -Christophe J. Godlewski, novembre 2006

D.R. $\mathrm{n}^{\circ} 82$ "Why do banks ask for collateral and which ones ?”, Régis Blazy - Laurent Weill, décembre 2006

D.R. $n^{\circ} 83$ "The peace of work agreement : The emergence and enforcement of a swiss labour market institution”, D. Broussolle, janvier 2006.

D.R. $\mathrm{n}^{\circ} 84$ "The new approach to international trade in services in view of services specificities : Economic and regulation issues”, D. Broussolle, septembre 2006.

D.R. $n^{\circ} 85$ "Does the consciousness of the disposition effect increase the equity premium" ?, P. Roger, juin 2007

D.R. n 86 "Les déterminants de la décision de syndication bancaire en France”, Ch. J. Godlewski

D.R. n 87 “Syndicated loans in emerging markets”, Ch. J. Godlewski / L. Weill, mars 2007

D.R. $n^{\circ} 88$ "Hawks and loves in segmented markets : A formal approach to competitive 
aggressiveness”, Claude d’Aspremont / R. Dos Santos Ferreira / J. Thépot, mai 2007

D.R. n 89 “On the optimality of the full cost pricing”, J. Thépot, février 2007

D.R. $n^{\circ} 90$ "SME's main bank choice and organizational structure : Evidence from France”, H. El Hajj Chehade / L. Vigneron, octobre 2007

D.R n 91 “How to solve St Petersburg Paradox in Rank-Dependent Models” ?, M. Pfiffelmann, octobre 2007

D.R. $\mathrm{n}^{\circ} 92$ "Full market opening in the postal services facing the social and territorial cohesion goal in France”, D. Broussolle, novembre 2007. 